\title{
EFFECT OF LEACHING HIGH ASH COAL BY HYDROFLUORIC ACID AND EDTA ON REMOVAL OF MINERAL MATTER AND SULPHUR
}

\author{
Manoj B. ${ }^{*}$, Kunjomana A.G. ${ }^{* *}$ and Mansoor Ahmad***
}

\begin{abstract}
Demineralization of coal was carried out using EDTA and HF. The residual coal from each treatment was characterized together with virgin coal using Scanning Electron Microscopy and energy dispersive $X$-ray analysis (EDAX). An elemental analyzer was adopted to analyze CHNS on virgin and residual coal sample. The current research compares the leaching efficiency of a mild leachant and a strong leachant. The final analysis showed that the coal under study was subbituminous coal and leaching could improve the amount of carbonaceous material. It was observed that with HF leaching aluminates silicates and calcites are removed completely where as only feaces of sulphur remained. With EOTA leaching only calcium was removed. The Carbon content is increased to 77.461 from 60.121 .
\end{abstract}

Keywords: Coal, Minerals, Characterization, SEM, EDAX.

* Dept. of Physics, Christ University, Hosur Road, Bangalore -29 Karnolaka, India, Tel: +91 80 40129340 Fox: 918040129000 E mail: manoj.b@christuniversity.in

** Dept. of Physics, Christ University, Hosur Road, Bangalore -29

***Corresponding author 


\section{Introduction}

Fossil energy, particularly derived from coal, had been investigated from various angles. Many environmentalists see coal as inherently dity. Coal minerals are considered objectionable due to the process as well as environmental problems. Coal minerals might be epigenetic and syngentic. Both constifute the inorganic part of the coal and if its concentration increases above a certain level, it is hazardous to the environment and the furnace. Minerals are needed to certain levels due to the catalytic effects in gasification and liquefaction [1-2]. Efforts are needed to reduce the ash forming inorganic elements and develop clean methods of using coal. Demineralization prior to utilization is an effective way to ensure environmental friendly combustion of coal as a fuel.

Many techniques were employed for coal beneficiation in order to demineralize and desulphurise coal [1-7]. Among these methods, leaching of coal with different leachants is presently carried out worldwide [1, 6-7]. Mineral acids are generally used to demineralize the coals but due to their strong oxidizing power, they modify the coal surface morphology, harm the carbon, reduce the calorific value and create environmental problems. Mild leachants are generally used to avoid such disadvantages.

In the present investigation, coal sample was collected from Godavari coal field, characterized and then subjected to leaching with leachants like HF and EDTA. The objective was to reduce mineral content and sulphur to overcome deleterious effects associated with combustion of low rank coal, without harming the carbon content of coal and compare the leachability of EDTA with mineral acid HF.

\section{Materials and Methods}

\subsection{Preparation of Coal sample}

The sample was randomly hand picked from a mine in Godavari coal field. It was crushed and ground in a pestle and mortar, screened through 250 micrometer sieves using a sieve shaker. The definite sized coal sample was dried in a vaccum oven at $70^{\circ} \mathrm{C}$ for one hour and cooled in a dessicator. The ultimate analysis of the virgin coal and residual coal under study is provided in Table 1. 


\subsection{Extraction procedure}

10 grams portion of the coal sample under study was extracted separately with 0.1 N EDTA for 24 hrs and concentiated HF (20\%) for thour. The specified amount of coal was slurried in $40 \mathrm{ml}$ extracting solution in a beaker. The content was stirred for lhour at $30^{\circ} \mathrm{C}$. After being treated for the specified duration of time, the slurry was filtered using a filter paper to remove the capture solution. The residual coal was washed with distilled water and dried in vacuum oven at $70^{\circ} \mathrm{C}$ till constant mass. The use of scanning electron microscopy (SEM) and energy dispersive X-ray (EDAX) analysis has many current and potential applications for the coal and mineral processing industries. It is used to investigate the formation and deposition of unwanted ash by-products and in analyzing substances of environmental concern.

\subsection{EDAX analysis}

Energy dispersive X-ray spectrophotometer (EDAX) model JSM 840A from JEOL company in Japan was used for the mineral analysis of treated and virgin coals.

\subsection{SEM Analysis}

The SEM micrographs of the virgin and residual coal samples obtained by Scanning Electron Microscope (SEM) model JSM 6390 from JEOL company in Japan.

\subsection{Elemental Analysis}

Elemental analysis was carried out using Vario EL III CHNS analyzer. The analysis was able to determine CHNS on dried samples. Oxygen content is obtained subtracting the total weight of the carbon, hydrogen, nitrogen and sulphur from the total.

\section{Results and Discussion}

Energy dispersive $X$-ray spectrophotometric (EDAX) study of the virgin coal and residue was conducted to study and compare the leachability of various leachants used. EDAX spectra of virgin sample and treated coals were given in Figures 1-3. It was evident from the Figure 1 and CHNS analysis (tablel) that the coal under study had carbon (60.12\%), oxygen (31.107\%), Al (25.66\%), Si (53.87\%), S (9.04\%) 
and $\mathrm{Ca}(11.43 \%)$. It was observed from the CHNS study that the carbon content increased to $69.12 \%$ when leached with EDTA for $1 \mathrm{hr}$. It was inferred from the EDAX analysis (Figure 2) that lithophilic elements like Ca was completely removed whereas sulphur content was reduced considerably $[1,4,6,8]$. It was also noticed that the aluminium and silicates content did not decrease with EDTA leaching.

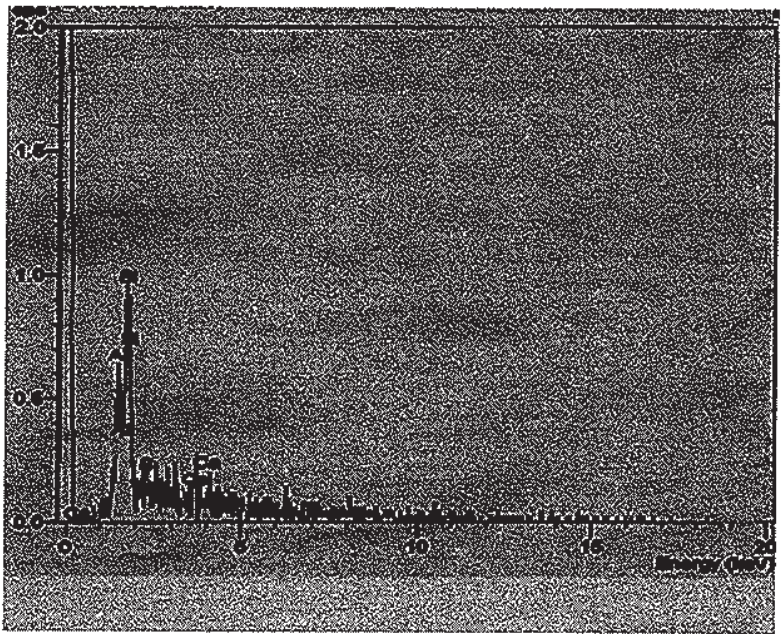

Figure 1: Virgin coal sample

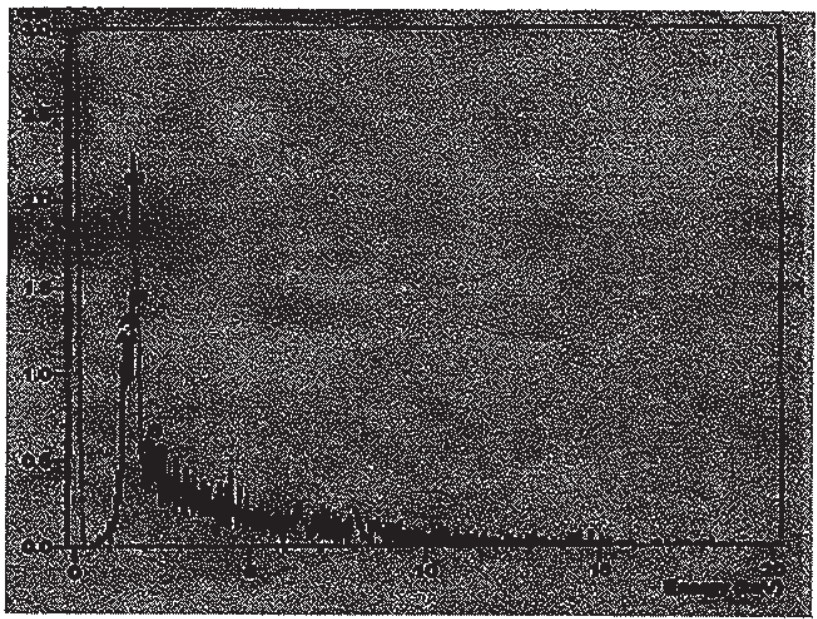

Figure 2: EDTA leached sample 


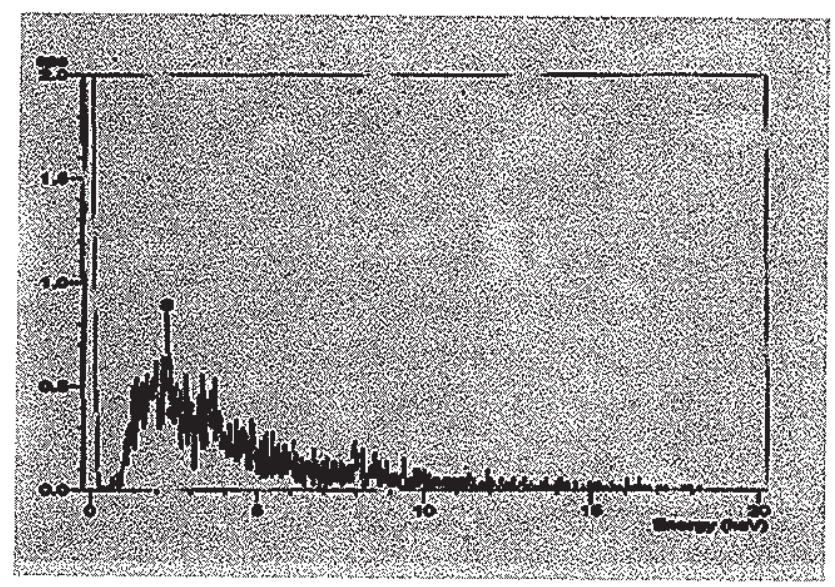

Figure 3: HF Leached sample

When the sample was leached with strong leachant like HF (Figure 3), almost all minerals (silicates, aluminates and calcites) were removed and only a trace amount of sulphur was present in the sample. It was matched with CHNS analysis where the sulphur content was reported to be at very low level of $0.016 \%$. During the leaching the carbon content showed an increase of $28.842 \%$ from the initial value.

\subsection{SEM Observation}

The SEM micrographs of the virgin and variously leached samples were provided in Figures 4-6. Figure 4 represents the SEM image of the virgin coal sample. A bulk microstructure composed of homogeneously distributed network of small crystallites showed the presence of minerals. In the matrix, luminous as well as non luminous features could be seen. These features indicate the presence of minerals distributed in the organic matrix. Many fissures, cleats, cracks and veins were also observed. The bright luminosity was due to the presence of aluminium, potassium or sodium. The dark luminosity was mainly due to the presence of chalcophiles $[1,5]$. Etiched pits, layers, some islands and hills \& valleys could also be seen randomly distributed through the micrograph. These might had resulted from the calcinations of dolomite and calcites or their assemblages due to thermal shock during metamorphism. It was inferred that the coal under study contain large proportions of dilica, calcium carbonates and dolomite, as well as some proportions of elements such as aluminium, potassium and sulphur. 


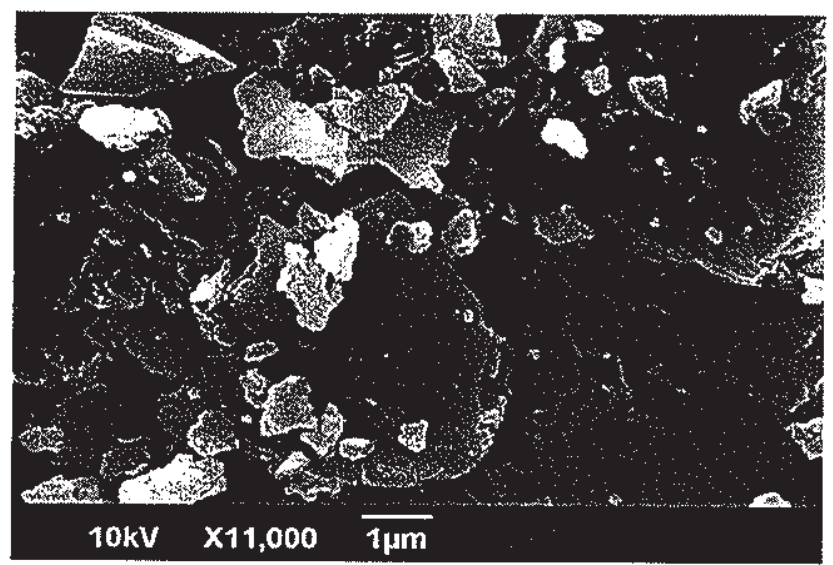

Figure 4: SEM micrograph of virgin sample

To remove the minerals and enrich the coal in usable carbon, chemical leaching was performed. The sample was leached with a chelating agent (EDTA) for 1 hour and the SEM of the residual coal was taken (Figure 5).

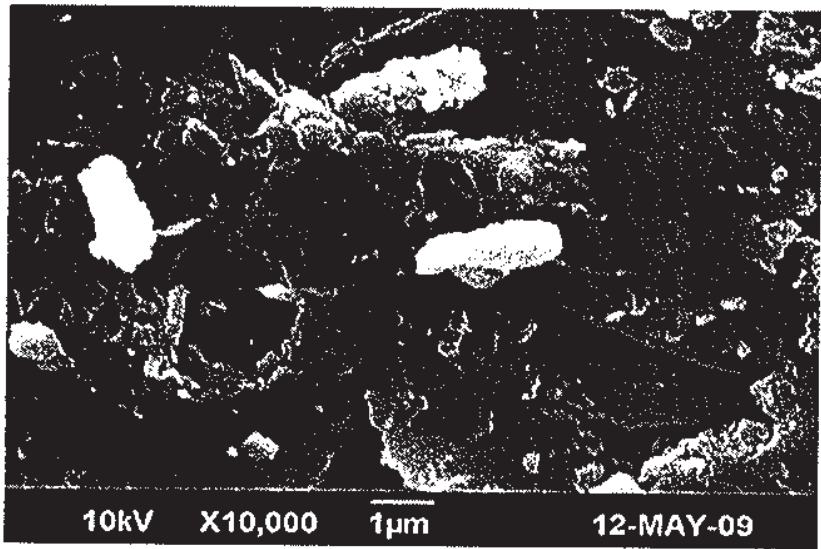

Figure 5: SEM micrograph of EDTA leached sample

The SEM study (Figure 5) reveals that the EDTA leaching did not harm the carbon. From the EDAX study it was also noticed that the mineral content especially the sulphur content decreases to minimum when treated with EDTA. Numerous aggregated particle could be seen on the suface. The increase of porosity was an indication that significant amount of inorganic elements were being removed. However, the surface coverage was still bright and luminous indicating the presence of mineral phases. 
Leaching was also performed with Hydrofluric acid (HF). The SEM image of the residual coal from this treatment was provided in Figure 6 . It could be seen that this leahant caused morpholigical changes in the particle and did enormous harm to the surface by leaching many of the inorganic elements.

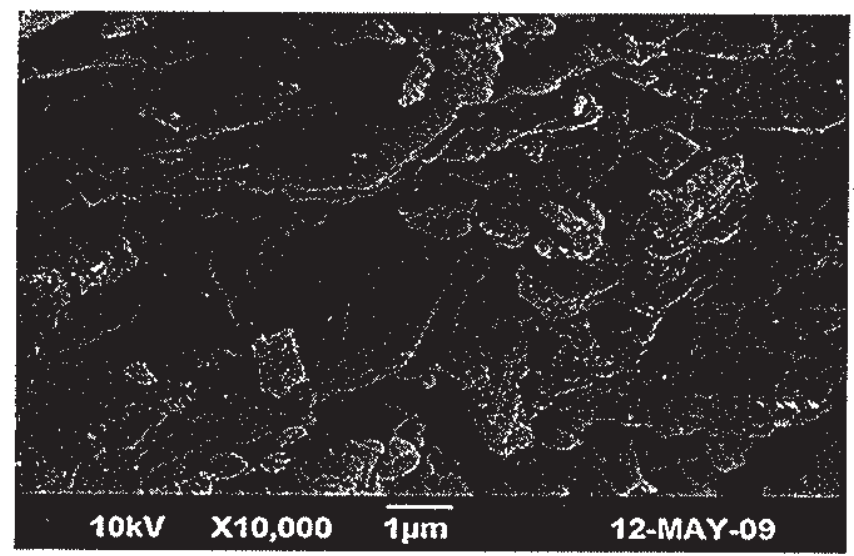

Figure 6: SEM micrograph of HF leached sample

Upon comparing different micrograph(Figure 4-Figure 6), it could be concluded that amongst the leachants used, $\mathrm{HF}$ was very effective for removing mineral matter like silicates and aluminates. EDTA leaching could remove calcites completely and leach the sulphur content partially.

Table I showed that demineralization using HF and EDTA leaching modified the ultimate and EDAX analyis of the sample. There was an appreciable reduction in the sulphur and oxygen content from the virgin sample [6-7].

EDTA could remove certain amount of minerals and oxygenated functional groups from the sample.

\section{Conclusion}

Bauxite and silicate minerals were most abundant in the sample along with calcites and a trace of sulphur. It showed a dense, shining and blocky structure by the SEM analyses.

It was inferred from the EDAX analysis that EDTA and HF leached the lithophilic elements like calcium effectively. The EDTA leaching could partially remove sulphur content from the sample whereas the HF could remove a majority of sulphur from the sample. It was also observed that HF was a successful leachant for leaching 
silicates, aluminates and calcites from the sample. From the CHNS analysis it was clear that leaching could substantially decrease the sulphur and oxygen content of the sample while increasing the carbon content.

The SEM image of the residual coal from $\mathrm{HF}$ treatment revealed that this leachant had caused morphological changes in the sample and did enormous change to the surface by leaching many of the inorganic elements. In the SEM of residual sample leached with EDTA, numerous aggregated particle could be seen. The increase of porosity was an indication that significant amount of inorganic elements were being removed. However, the surface coverage was still bright and luminous indicating the presence of mineral phases.

Upon comparing different micrographs, it was concluded that amongst the leachants used $\mathrm{HF}$ was very effective in leaching mineral matter than EDTA. This result was in good agreement with the findings of EDAX and ultimate analysis.

Table 1. EDAX Analysis and Ultimate Analysis

\begin{tabular}{|c|c|c|c|c|c|}
\hline Sample & \multicolumn{3}{|c|}{ EDAX Analysis } & \multicolumn{2}{c|}{ Ultimate Analysis } \\
\hline \multirow{4}{*}{ Virgin coal } & \multicolumn{2}{|c|}{ Elemental\% } & Atomic \% & C & $60.12 \%$ \\
\cline { 2 - 4 } & $\mathrm{Si}$ & 53.87 & 55.82 & $\mathrm{H}$ & $6.840 \%$ \\
& $\mathrm{Al}$ & 25.66 & 27.67 & $\mathrm{~N}$ & $1.469 \%$ \\
& $\mathrm{~S}$ & 09.04 & 8.21 & $\mathrm{~S}$ & $0.464 \%$ \\
& $\mathrm{Ca}$ & 11.43 & 8.30 & O(diff) & $31.107 \%$ \\
\hline Sample leached & $\mathrm{Si}$ & 67.83 & 67.73 & $\mathrm{C}$ & $69.44 \%$ \\
with EDTA & $\mathrm{Al}$ & 25.67 & 26.61 & $\mathrm{H}$ & $2.730 \%$ \\
& $\mathrm{~S}$ & 6.47 & 5.66 & $\mathrm{~N}$ & $1.468 \%$ \\
& $\mathrm{Ca}$ &.-- & -- & $\mathrm{S}$ & $0.070 \%$ \\
& & & & O(diff) & $26.29 \%$ \\
\hline \multirow{2}{*}{ Sample leached } & $\mathrm{Si}$ &.- &.- & $\mathrm{C}$ & $77.46 \%$ \\
with HF & $\mathrm{Al}$ & -- & -- & $\mathrm{H}$ & $4.432 \%$ \\
& $\mathrm{~S}$ & Trace & Trace & $\mathrm{N}$ & $1.932 \%$ \\
& $\mathrm{Ca}$ &.- &.- & $\mathrm{S}$ & $0.016 \%$ \\
& & & & O(diff) & $16.16 \%$ \\
\hline
\end{tabular}




\section{References}

(1] Mohammad, Shakirullah, Imtiaz Ahmad, Mohammad Arsala Khan, Mohammad Ishaq, Habib ur Rehman, and Uzma Khan. (2006), "Leaching of Minerals in Degari Coal." Journal of Minerals \& Material Characterization and Engineering, Vol.5, No. 2, pp.131. 142.

[2] . Özłas, N.A. and Yürüm, Y. (2000). "Pyrolysis of Turkish Zonguldak bituminous coal. Part 1 Effect of minerol matter," Fuel., Vol.79, pp.1221-1227.

[3]. Qing-feng, Xue. and Sheng-gao, Lu. (2008). "Microstructure of ferrospheres in fly ashes: SEM, EDX and ESEM analysis."J Zhejiang Univ Sci A, Vol.9 No 11, pp. 1595-1600.

[4]. M. Shakirullah, I. Ahmad, M. Ishaq, H. Rehman, and U. Khan, H. Ullah (2006). "Effective Chemical Leaching and Ash Depletion of low rank coal with EDTA and Citric acid." Jour.Chem.Soc.Pak., Vol. 28 No. 1, pp. 56 - 61.

[5]. Chin-min Cheng. (2005). "Leaching of Coal combustion products Field and Laboratory studies," PhD thesis, Ohio State University, pp. 110-181.

[6]. Wenfeng Wang, Yong Qin, Shuxun Sang, Bo Jiang, Yingming Zhu, Yinghai Guo. (2007). "Sulphur variability and element geochemistry of the No.11 coal seam from the Antaibao mining district, China." Fuel, Vol.86, pp. 777.784.

[7]. F. Rubiera, A. Arenillas, B. Arias, J.J. Pis, I.Suarez-Ruiz, K.M.Steel, J.W. Patrick. (2003). "Combustion behaviour of Ultra clean coal obtained by chemical demineralization", Fuel., Vol.82, pp. 2145-2151.

[8]. Tao Wu, Mei Gong, Ed Lester, Fuchen Wang, Zhijie Zhou and Zunbong Y. (2007) "Characterization of residual carbon from entrained-bed coal water slurry gasifiers," Fuel., Vol. 86, pp. 972-982. 